\title{
Assessment of Knowledge, Attitude and Perceived Practices on the Importance of Folate Among Filipino Women of Child-bearing Age in the Province of Batangas
}

\author{
Aiza Kris M. Bernardo \\ Institute of Human Nutrition and Food, College of Human Ecology, University of the Philippines Los Baños
}

\begin{abstract}
Objectives. Folate is an essential nutrient associated with healthy pregnancy outcomes. Women of child-bearing age (WOCBA) are advised to maintain optimum blood folate status through adequate dietary folate intakes and folic acid from supplements. This study was aimed at assessing the level of knowledge, attitude, and perceived practice (KAP) among WOCBA on the importance of folate periconceptionally.

Methods. A cross-sectional survey was conducted among 184 healthy WOCBA in the Province of Batangas. The level of KAP was expressed as percent mean scores and were interpreted as poor, moderate, or high for knowledge and perceived practices and negative, neutral, or positive for attitude. Pearson's correlation of coefficient was used to measure the linear correlation between variables at a $95 \%$ level of significance.

Results. About $70 \%$ of respondents have heard of folate. The study showed a moderate level of knowledge, positive attitude, and moderate perceived practices related to folate among WOCBA. Age and civil status were associated with KAP. A significantly weak positive association $(r=0.4, p<0.000)$ between the level of attitude and perceived practice related to folate was observed. Further, the level of knowledge showed significantly positive moderate association to attitude $(r=0.7, p<0.000)$ and perceived practice $(r=0.5, p<0.000)$.

Conclusion. Increasing the level of knowledge on folate suggests a positive attitude and a higher level of perceived practice. The findings of the study suggest a need to increase knowledge on folate among WOCBA, especially, in younger women. Also, there is a need to emphasize the importance of adequate folate intakes from food and folic acid supplements, periconceptionally.
\end{abstract}

Key Words: knowledge, attitude, perceived practices, folate, women of child-bearing age

\section{INTRODUCTION}

Corresponding author: Aiza Kris M. Bernardo Institute of Human Nutrition and Food College of Human Ecology

University of the Philippines Los Baños UP College, Los Baños, Laguna, Philippines

Email: ambernardo1@up.edu.ph
Folate is an essential nutrient related to proper fetal development. It plays a key role in several metabolic pathways during pregnancy including those leading to RNA and DNA synthesis. Folate acts as a coenzyme facilitating the transfer of carbon to nucleic and amino acids. During periods of rapid cell division, i.e., growth of fetus and expanding organs in pregnancy, folic acid requirements increase. This is because more folate is needed to facilitate the carbon transfer reactions and support the rapid periods of cell division. ${ }^{1}$ Folate or folacin is a B-vitamin that can be obtained through the intake of folate-rich foods and supplements. Folic acid from supplements and fortified foods are considered more bioavailable than folate from dietary sources. ${ }^{2}$ Total folate 
intake is expressed using dietary folate equivalents (DFE). Filipino WOCBA is advised to consume $320 \mathrm{ug}$ DFE per day according to the estimated average requirement developed by the Food and Nutrition Research Institute-Department of Science and Technology. ${ }^{3}$ Apart from maintaining adequate folate from the diet, folate deficiency in the Philippines poses a major threat to maternal and child health. According to the $7^{\text {th }}$ National Nutrition Survey, $20.9 \%$ (or about 1 in 5) Filipino women of childbearing age are folate deficient based on red cell folate count, while $38.7 \%$ (or about 2 in 5) are folate deficient based on serum folate. ${ }^{4}$

Not long after the folic acid discovery, a relation between folate and neural tube defects (NTDs) was first suggested by Hibbard in 1964. Researches on NTDs focused on the mechanism by which folic acid affects fetal growth and has found several reasons. Firstly, the relative importance of congenital malformations, in general, has increased as other major causes of fetal and infant morbidity and mortality (i.e., preterm birth, infections) have come under control. Furthermore, NTDs are common (the most common malformations of the central nervous system and probably second only to cardiac defects among major congenital anomalies) and they represent a major public health problem by virtue of their mortality, morbidity, social cost, and human suffering. Finally, and perhaps the most important, maternal folic acid supplementation prevents a substantial proportion of NTDs. It was recognized for the first time, a situation in which a congenital defect is amenable to preventive measures. ${ }^{5}$ Congenital malformations which include NTDs remain in the top ten leading causes of infant mortality from 1960 to 2005 in the Philippines. ${ }^{6}$ While 20\% to almost 40\% is folate inadequate, the number of cases of birth anomalies related to folate deficiency has increased significantly.

The assessment of nutrition-related knowledge, attitude, and practices offers an opportunity to better understand a given situation by providing insights into the social, psychological, and behavioral determinants of nutritional status. In nutrition, knowledge is the understanding of nutritionrelated topics, including the intellectual ability to recall food- and nutrition-related terminology, specific pieces of information and facts. Attitudes are emotional, motivational, perceptive, and cognitive beliefs that positively or negatively influence the behavior or practice of an individual. Attitude, belief, and perception are interchangeable, and so, the perceived practice reflects the attitude of being self-confident in doing a nutrition-related practice. Self-confidence, as subsumed under attitude, refers to an individual's belief regarding his or her own ability to perform a practice or his or her confidence in doing so. ${ }^{7}$

This current study was aimed at assessing the level of KAP related to folate among WOCBA. KAP on folate is of public health significance now that folate deficiency among Filipino women is at an alarming number. It can provide valuable inputs for effective programs related to the improvement of folate status, such as health and nutrition education. This study was conducted in an area that nearly represents a rural and urban setting. Batangas is one of the five provinces in the region of CALABARZON which has the highest number of live births delivered by mothers age 15 and below and $15-49$ years. In addition, CALABARZON is second to NCR as the highest number of deaths caused by conditions originating from pregnancy. Deaths caused by congenital anomalies are at a 7\% rate with a total number of 894 in CALABARZON and 114 per 100,000 population in Batangas. This number is highest in the country. ${ }^{8}$

\section{MATERIALS AND METHODS}

A cross-sectional survey was conducted in the Province of Batangas from May to July 2017. A total of 184 pregnant and non-pregnant women age 15-49 years, residents of the Province of Batangas participated in the study. A total sample size of $n=200$ with a $5 \%$ replacement was computed based on a $7 \%$ margin of error, 0.25 variability ( $\mathrm{p}=0.25)$, and a $90 \%$ level of confidence. The response rate was $92 \%$. Due to a lack of a complete listing of women in the entire province, the selection of participants was conducted per barangay using equal cluster sampling. Of the 1,078 barangays in Batangas, eight barangays were randomly selected, namely: Poblacion 1 Santo Tomas Batangas, Bilucao Malvar, Leynes Talisay, Poblacion 8 Lipa City, Rizal Lipa City, Inosluban Lipa City, Poblacion 1 Bauan, Makina Calaca, from where respondents were drawn from. A complete list of women per selected barangay was obtained and 25 respondents were randomly selected from each barangay.

Using a face-to-face interview, the survey was started with preliminary questions to assure that respondents have no serious health concerns before the interview. Questions include: (1) Have you had an illness in the past three months?; (2) Do you have current medical ailments related to diseases of the cardiovascular, kidney, abdominal, or respiratory function?; and, (3) Do you take medications for high blood pressure, cancer, epilepsy, and other drugs for serious medical conditions?. Respondents who answered "Yes" in any of the questions were excluded and replaced in the study. To further analyze the respondents' level of KAP, initial awareness of folate was determined. Awareness, as used in this study, was defined as knowing that something exists. General awareness sits at the lower end of the continuum of the knowledge domain, where detailed knowledge sits at the higher end ${ }^{9}$. Respondents were asked if they have ever heard of folate or folic acid. Respondents who answered "Yes" proceed with the succeeding questions on knowledge, attitude, and perceived practices. On the other hand, respondents who answered "No" were not asked further and were automatically dropped from answering the rest of the survey. Moreover, the study consisted of multiple parameters such as a sociodemographic and socioeconomic profile of respondents.

Assessment of knowledge, attitude, and perceived practices used a three-part survey questionnaire answerable 
by "yes" or "no". Some of the questions were adapted from previous studies of KAP on folate. ${ }^{10,11,12}$ Correct answers were scored one point each while incorrect answers were given zero points. Scores were recorded and interpreted as percent scores. Interpretation of percent scores for KAP was partially adapted from the study conducted by Keshavarzi et. al. about peri-conceptional folic acid usage pattern in Malaysian women. ${ }^{13}$ Before the actual conduct of the study, the questionnaires were pre-tested among 39 pregnant and non-pregnant women age 15 to 49 years in the Brgy health center of Sta Elena Sto. Tomas Batangas and in the primary health care Basic Emergency Obstetric and Newborn Care (BEmONC) clinic in Santo Tomas Batangas.

The first part was the assessment of knowledge on the importance of folate. A 10-point questionnaire was used to assess the level of knowledge among respondents. All statements included in the knowledge survey questionnaire were correct. "Yes" answers were given one point and "No" answers zero points. Percent score of 30\% and below was interpreted as a poor level of knowledge; a $40-70 \%$ score as a moderate level of knowledge; and, score of $80 \%$ and above indicates a high level of knowledge on folate.

The second part includes respondents' assessment of attitude on the importance of folate. A 5-point survey questionnaire was used in the study. All five statements were indicating a positive attitude. "Yes" answers also scored a point and "No" answers scored zero points. A percent score of $30 \%$ and below was interpreted as a negative attitude. Whereas, a score of $40-70 \%$ was interpreted neutral and positive attitude scores $80 \%$ and above.

The third and last part of the survey includes respondents' assessment of their perceived practices related to folate. A 5 -point survey questionnaire was also used in the study. All five statements were the expected perceived practice. "Yes" answers also scored a point and "No" answers scored zero points. A percent score of $30 \%$ and below was interpreted as poor perceived practice. Whereas the score of $40-70 \%$ was interpreted a moderate level of perceived practice and a high level of perceived practice scores $80 \%$ and above.

The data were analyzed descriptively and inferentially. Descriptive statistics were employed to describe data in terms of frequency and percentages for categorical variables while means and standard deviation were used to describe continuous variables. Pearson's product-moment correlation of coefficient, denoted as $r$, was used to measure the strength of linear correlation between variables. Test of association between a continuous variable and a categorical variable with two levels was carried out using Pearson's Correlation. Statistical results were interpreted at a 95\% level of significance.

Ethical clearance of the study was sought from the Ethics Review Committee (ERC) at the Research Institute for Health Sciences (RIHS), University of the East Ramon Magsaysay Memorial Medical Center, Inc. (UERMMMCI) with RIHS ERC Code: 0482/E/O/17/141.
This study was part of a larger study entitled "Predictors of Red Blood Cell Folate Status among Women of Childbearing Age (15-49 years) in the Philippines".

\section{RESULTS}

\section{Demographic and socio-economic profile}

The mean age of the respondents was 32.89 years \pm 0.85 (31.21 years, 34.57 years, CI 95\%). About two-thirds $(66.3 \%, \mathrm{n}=113)$ belonged to the age group 30 years and above. The majority $(79 \%, n=134)$ of the population are married and or living with a partner. Almost all (94.2\%, $\mathrm{n}=171$ ) respondents were Catholic. More than half of the respondents have reached at least a high school level of education (59\%, $n=117)$. About 33\% $(n=57)$ have reached at least college or postgraduate education while $8 \%(n=10)$ have no formal education or at least have reached elementary level. Almost half $(41.4 \%, \mathrm{n}=90)$ of the respondents were employed or with their own business. Those who have reached high school accounted for the highest number of women employed at $52 \%(\mathrm{n}=47)$. Correspondingly, $74 \%$ of women unemployed were those women who have reached at least a high school level of education. There was a significant association between education categorized in the number of years (12 years below and above) and the status of employment ( $\mathrm{p}<0.0001)$. Among the respondents 19\% $(n=23)$ were household heads. Among them, 92\% were at least have reached the high school level of education. Results showed that there is a significant association between the level of education among women and being a household head $(\mathrm{p}=0.0025)$. Among household head respondents, $65 \%$ were employed. A significant association was also found between employment and household headship ( $\mathrm{p}=0.0034)$.

The mean household monthly income was computed at 13,942 pesos \pm 1468 ( 11,044 pesos, 16,838 pesos, CI $95 \%$ ). More than one-third $(43.5 \%, \mathrm{n}=67)$ met this amount for food and non-food expenses while 56.5\% ( $\mathrm{n}=117)$ have income below the poverty threshold. Among them, $53 \%$ were unemployed. Among the respondents with monthly income above the poverty threshold, $n=67,52 \%$ were employed. Regardless of employment status, the majority of women of reproductive age reported an income below the minimum value to suffice for food and non-food expenditures.

House and vehicle ownership and access to electricity were socioeconomic predictors of poverty. The study showed more than half of respondents owned their houses $(57.1 \%$, $n=105)$. About $15 \%(n=29)$ were renting their house, while, $28 \%(\mathrm{n}=50)$ were living with parents or in-laws or residing in the non-owned houses for free. Among respondents without an owned house, $71 \%$ were living below the poverty line. House ownership was associated with education $(\mathrm{p}=0.0018)$ but not with employment status. Moreover, the majority (97\%) of households with women of reproductive age have access to electricity. About half of the respondents (43.4\%) owned a vehicle. Among them, 28\% ( $\mathrm{n}=51)$ were living in 
Table 1. Sociodemographic and socio-economic profile of respondents, $n=184$

\begin{tabular}{|c|c|c|c|}
\hline Variables & Category & Mean, SD (95\% Cl) & Frequency distribution (n, \%) \\
\hline Age, years & $\begin{array}{l}15 \text { to } 19.0 \text { years } \\
19.1 \text { to } 29 \text { years } \\
30 \text { to } 49 \text { years }\end{array}$ & $32.89 \pm 0.85$ (31.21 34.57) & $\begin{array}{r}15(7) \\
56(26.7) \\
113(66.3) \\
\end{array}$ \\
\hline Civil status & $\begin{array}{l}\text { Single } \\
\text { Married/Lived-in } \\
\text { Separated/Widowed/Divorced }\end{array}$ & & $\begin{array}{r}44(15) \\
134(79) \\
6(6)\end{array}$ \\
\hline Religious affiliation & $\begin{array}{l}\text { Roman Catholic } \\
\text { Muslim } \\
\text { Iglesia Ni Cristo } \\
\text { Evangelicals } \\
\text { Others, specify } \\
\end{array}$ & & $\begin{array}{c}171(94.2) \\
1(0.6) \\
4(1.4) \\
4(2.2) \\
4(1.6) \\
\end{array}$ \\
\hline Educational attainment & $\begin{array}{l}\text { No formal education } \\
\text { Have reached elementary education } \\
\text { Have reached high school education } \\
\text { Have reached college education or higher }\end{array}$ & & $\begin{aligned} & 1(0.6) \\
& 9(7.9) \\
& 117(58.9) \\
& 57(32.6) \\
&\end{aligned}$ \\
\hline Employment & $\begin{array}{l}\text { Student/unemployed } \\
\text { Employed/self-employed }\end{array}$ & & $\begin{array}{l}94(41.4) \\
90(58.6)\end{array}$ \\
\hline Household head & $\begin{array}{l}\text { No } \\
\text { Yes }\end{array}$ & & $\begin{array}{r}161(81) \\
23(19) \\
\end{array}$ \\
\hline House ownership & $\begin{array}{l}\text { Owned } \\
\text { Rented } \\
\text { Residing for free } \\
\text { Living with parents/in-laws }\end{array}$ & & $\begin{array}{r}105(57.1) \\
29(14.9) \\
23(12.1) \\
27(15.9) \\
\end{array}$ \\
\hline Vehicle ownership & $\begin{array}{l}\text { No } \\
\text { Yes }\end{array}$ & & $\begin{array}{r}108(56.6) \\
76(43.4)\end{array}$ \\
\hline Access to electricity & $\begin{array}{l}\text { No } \\
\text { Yes }\end{array}$ & & $\begin{array}{c}2(2.8) \\
182(97.2) \\
\end{array}$ \\
\hline Access to market & $\begin{array}{l}\text { No } \\
\text { Yes }\end{array}$ & & $\begin{array}{r}68(42.2) \\
116(57.8) \\
\end{array}$ \\
\hline $\begin{array}{l}\text { Backyard vegetable gardening } \\
\text { and or livestock raising }\end{array}$ & $\begin{array}{l}\text { No } \\
\text { Yes }\end{array}$ & & $\begin{array}{r}118(62.2) \\
66(37.8)\end{array}$ \\
\hline
\end{tabular}

Table 2. Mean percent KAP scores, $n=129$

\begin{tabular}{lcc}
\multicolumn{1}{c}{ Items } & Mean score & Interpretation \\
Knowledge & 77 & Moderate level \\
Attitude & 82 & Positive \\
Perceived practice & 71 & Moderate level \\
\hline
\end{tabular}

Table 3. Frequency distribution of respondents according to the level of knowledge, attitude and perceived practices, $n=129$

\section{Level of KAP Knowledge Attitude Perceived practices}

\begin{tabular}{lrrr} 
Poor/Negative & 17 & 11 & 4 \\
Moderate/Neutral & 39 & 18 & 56 \\
High/Positive & 80 & 100 & 69 \\
Total & 129 & 129 & 129 \\
\hline
\end{tabular}

an owned house, 20\% ( $n=37)$ have monthly income above the poverty line. However, only $15 \%(n=27)$ of respondents owned a house, a vehicle, and living above the poverty line. On the contrary, $50 \%$ of the respondents still have difficulty accessing the market even if they owned a vehicle.
In this present study, about one in every three $(37.8 \%$, $\mathrm{n}=66$ ) women of reproductive age have vegetable backyard gardens and or practice livestock raising. Among them, 68\% have income below the poverty threshold and 55\% have difficult market access. Further, $26 \%$ of the respondents, living below the poverty line, without easy market access, and were practicing vegetable gardening and or livestock raising. Table 1 listed down the summary of characteristics of respondents in terms of their sociodemographic and socioeconomic profiles.

Of the 184 respondents who participated in the study, $70 \%$ of respondents $(n=129)$ have heard of the term "folate" or "folic acid". The succeeding results described the level of KAP among 129 participants who showed initial awareness on the subject. Table 2 shows the mean KAP scores of respondents and Table 3 summarizes the frequency distribution of respondents according to the level of knowledge, attitude, and perceived practices.

\section{Knowledge on folate}

The mean knowledge percent score was $77 \%$ which reflected a moderate level of knowledge on folate among 
respondents. About eight percent $(n=10)$ of respondents have a poor level of knowledge. About one-third $(30 \%, n=39)$ have a moderate level while more than half $(62 \%, n=80)$ have a high level of knowledge. Among those who have heard about folate, $80 \%$ knew a little about the vitamin and $75 \%$ reported that they knew that folate comes from green leafy vegetables. Moreover, $62 \%$ knew folate is a member of B-vitamins and $83 \%$ were aware that folate is important among WOCBA. The majority (78\%) believed folate deficiency can lead to birth defects but only $68 \%$ knew it can also lead to infant death. More than half (67\%) knew that folic acid supplementation is important for WOCBA. Table 4 shows the result of the knowledge assessment per question asked.

\section{Attitude on folate}

The mean attitude score was computed at $82 \%$ which shows a positive attitude among respondents on the importance of folate. Among them, nine percent $(n=11)$ showed a negative attitude toward folate, and 14\% ( $\mathrm{n}=18)$ showed a neutral attitude. And about $78 \%(\mathrm{n}=100)$ showed a positive attitude. The majority believed that folate deficiency during pregnancy can result in birth defects (79\%) and folic acid supplementation is important among WOCBA (84\%). About $81 \%$ believed that frequent intakes of vegetables lead to adequate intake of folate while $76 \%$ also believed that there are other food sources of folate aside from vegetables. The majority (91\%) believed that it is important for WOCBA to maintain normal folate status.
Table 5 summarizes the result of attitude assessment per question asked.

\section{Perceived practices related to folate}

The mean percent score for the level of perceived practice was computed at $71 \%$. When interpreted, a score of $71 \%$ showed a moderate level of perceived practice related to folate among WOCBA. The poor perceived practice was observed in about three percent of respondents $(n=4)$ while $43 \%(n=56)$ showed moderate perceived practice. More than half (54\%, $\mathrm{n}=69$ ) showed a high level of perceived practice related to folate. Further, more than half (62\%) perceived that they can maintain normal blood folate levels but only (43\%) perceived they have normal blood folate during the survey. More than half (61\%) perceived taking folic acid supplements even when not pregnant. Moreover, the majority of the respondents showed interest in learning more about folate and agreed that with proper knowledge on folate sources they will be able to maintain normal folate levels. Table 6 summarizes the response per statement in the test for the level of perceived practice related to folate.

\section{Correlation of KAP to socio-demographic and socio-economic variables}

The study showed that age has a significantly positive association with knowledge $(\mathrm{r}=0.2, \mathrm{p}<0.01)$ and attitude $(r=0.2, p<0.04)$ percent scores. Age was not associated with the perceived practice. Knowledge score was associated with

Table 4. Summary of responses on the level of knowledge on folate, $n=129$

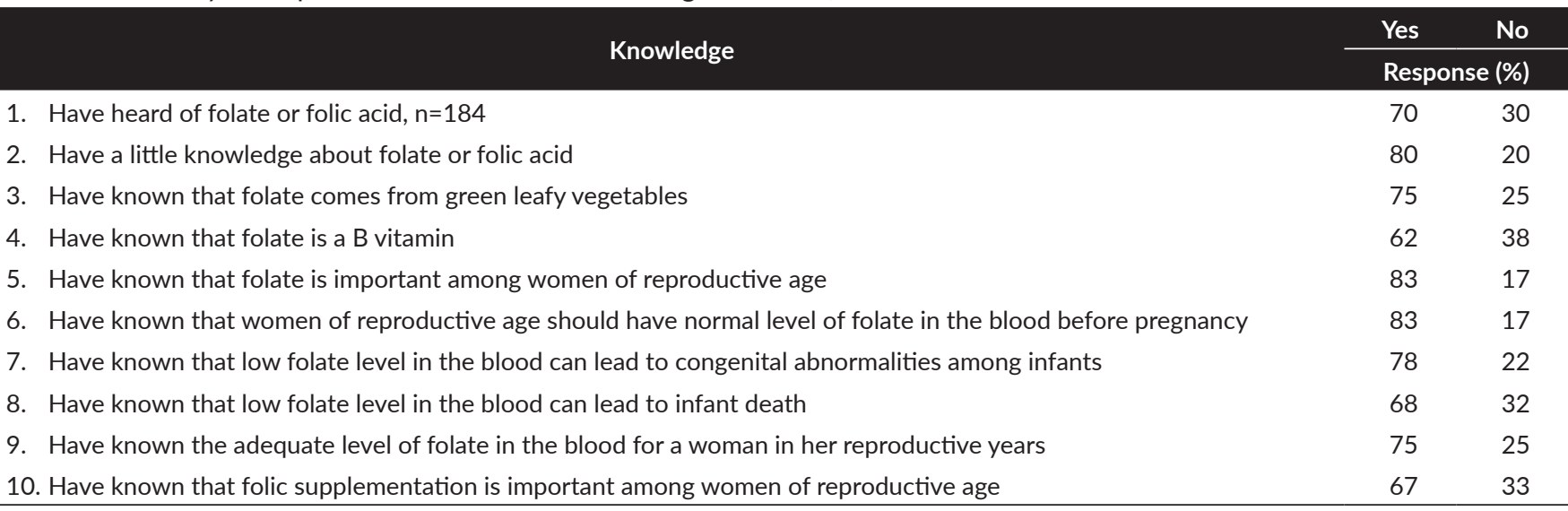

Table 5. Summary of responses on the level of attitude on folate, $n=129$

\section{Attitude}

1. I believe that inadequate folate in the diet and low folate status during pregnancy can lead to congenital malformations and death among infants

2. I believe that folic acid supplementation is important among women of reproductive age

3. I believe that frequent intake of green leafy vegetables can contribute to normal folate level in the blood

81

76

4. I believe that aside from green leafy vegetables, there are other food sources of folate and folic acid 
civil status $(\mathrm{r}=0.2, \mathrm{p}=0.05)$. Moreover, there was also a weak positive association between perceived practice related to folate and market access $(r=0.2, p=0.00)$. No relationship exists between KAP scores of women on folate and their education level.

\section{Correlation of knowledge, attitude, and perceived practice related to folate}

The over-all KAP study showed that there was a moderately significant positive correlation between the level of knowledge and attitude of respondents $(r=0.7, p<0.000)$ and their perceived practices related to folate $(\mathrm{r}=0.5$, $\mathrm{p}<0.000$ ). Women who have high knowledge tend to show a positive attitude on folate and perceived themselves to put knowledge into practice. Moreover, there is a weak positive association between attitude and the level of perceived practices related to folate respondents $(r=0.4, p<0.000)$. The results of the correlation analysis of KAP scores were summarized in Table 7 .

\section{DISCUSSION}

This study showed that WOCBA has a moderate (mean percent score of 77) level of knowledge related to folate. Among the respondents, about $70 \%$ have heard the term folate or folic acid. The study showed a lower number of respondents who showed awareness on folate considering the large proportion of respondents who belonged to age 19-49 years (93\%) and those who were married, lived-in, separated (85\%). The study. A similar result has been found among European women where $70 \%$ also have heard folate or folic acid. ${ }^{14}$ The results may also be indicative that a large number of women respondents in their reproductive years have never realized that they were being advised of or taking folic acid for reproductive health. On the contrary, the result of the present study showed a higher percentage of awareness compared to neighboring countries such as in the Middle East and Southeast Asia. A study among Qatari women showed that $53.7 \%$ of respondents have heard the term folate or folic acid. ${ }^{10}$ About the same number (67.5\%) have heard folate in the study of awareness, knowledge, and use of folic acid among non-pregnant Korean women of childbearing age. ${ }^{15}$ This present study also suggests that while respondents knew about folate (80\%), they have low knowledge of the effect of its deficiency as shown by only $68 \%$ who knew that folate deficiency can lead to infant death. Consequently, a lower number of women (67\%) knew that folic acid supplements are essential for WOCBA. Furthermore, similar results on awareness and attitude were observed from independent studies conducted locally. ${ }^{10,16}$ Even in countries with a known high prevalence of NTDs such as the case of China, only half of the respondents had heard of folic acid. ${ }^{17}$ It only supports that awareness of the importance of folate is still low.

In the study of Horn et. al. in 2014 among 130 women of child-bearing age, most of them know the sources of folic acid. ${ }^{18}$ However, no more than half of the respondents believed that folic acid contents may prevent congenital malformations such NTDs. Women who reported awareness of folic acid had greater folic acid knowledge and use of vitamins containing folic acid than those not aware. Analyses also examined the use of vitamins containing folic acid by pregnancy intention, an increase in the use of folic acidcontaining supplements was observed among women who reported awareness of folic acid. ${ }^{19}$

Further, the findings of the study showed that the mean percent knowledge score has a significant association with age $(r=0.2, p<0.01)$ and civil status $(r=0.2, p<0.05)$ but not with education. The level of knowledge increases with age. The mean age of women with poor knowledge level was 25.8 years, and 33.6 years for those with a high level of knowledge. Moreover, more than half $(64 \%, n=51)$ with a high level of knowledge belonged to $30-49$ years. The majority ( $83 \%$, $\mathrm{n}=66$ ) of respondents with high knowledge level were

Table 6. Summary of responses to statements on perceived practices related to folate, $n=129$

\begin{tabular}{|c|c|c|c|c|c|}
\hline \multirow{2}{*}{\multicolumn{4}{|c|}{ Perceived Practices }} & Yes & No \\
\hline & & & & \multicolumn{2}{|c|}{ Response (\%) } \\
\hline \multicolumn{4}{|c|}{ 1. I believe that I am able to maintain normal blood folate level } & 62 & 38 \\
\hline \multicolumn{4}{|c|}{ 2. I strongly believe that at the moment my blood folate level is within normal } & 43 & 57 \\
\hline \multicolumn{4}{|c|}{ 3. I believe that I should take folic acid supplements even if I'm not pregnant } & 61 & 39 \\
\hline \multicolumn{4}{|c|}{ 4. I am interested to learn more about folate and folic acid } & 98 & 2 \\
\hline \multicolumn{4}{|c|}{$\begin{array}{l}\text { 5. I believe that with proper knowledge of food rich in folate, I am able to consume them to maintain normal blood } \\
\text { folate level }\end{array}$} & 95 & 9 \\
\hline Items & Correlation coefficient, $r$ & Strength of correlation & $p$ value & \multicolumn{2}{|c|}{ Interpretation } \\
\hline Knowledge to attitude & 0.7 & moderately positive & $<0.000$ & \multicolumn{2}{|c|}{ Significant } \\
\hline Knowledge to perceived practice & 0.5 & moderately positive & $<0.000$ & \multicolumn{2}{|c|}{ Significant } \\
\hline Perceived practice to attitude & 0.4 & weak positive & $<0.000$ & \multicolumn{2}{|c|}{ Significant } \\
\hline
\end{tabular}


married or living with their partner. While questions related to obstetric history may be lacking in this study, there is an assumption that married life is equated to having children. And both of those experiences, marriage and having a child, may contribute to increasing the level of knowledge on folate. Education was not significantly associated with a level of knowledge, however, results showed that women with years of education below six years have a lower mean score of $60 \%$ compared to $78 \%$ mean score of those who have 12 years of education and beyond. Moreover, about $80 \%$ of those who have poor knowledge score has education below 12 years. Increase awareness of folate is dependent on education as shown in the study of Bener et. al. ${ }^{10}$ Consistently, Vollset and Lande revealed in their study of knowledge and attitudes of folate, and use of dietary supplements among women of reproductive age in Norway 1998 that education was the strongest determinant of knowledge on folate. ${ }^{20}$ The study only showed that as a woman ages, attends formal schooling and experiences married life, their level of knowledge related to folate increases.

Correspondingly, WOCBA showed a positive attitude toward the importance of folate ( $82 \%$ mean percent score). The respondents showed positive behavior that they can maintain adequate folate intake and normal blood folate through folate-rich food and supplements. The attitude was significantly associated with age $(r=0.2, p<.05)$. The mean age of respondents with negative attitudes was 25.8 years while 33.0 years was the mean age of respondents that showed a positive attitude on folate. While education showed no association with attitude scores, a higher number of respondents with education of at least 12 years have a positive attitude. According to the Organization for Economic Cooperation and Development, there is considerable international evidence that education is strongly linked to health and its determinants such as health behaviors. Those with more years of schooling tend to have better health and wellbeing and healthier behaviors. ${ }^{21}$ Moreover, civil status showed no association with attitude on folate but a significant number of married or women living with their partner scored high in the attitude test (70\%). The majority of single women showed neutral or negative attitude scores.

The level of perceived practice among WOCBA respondents was moderate (71\%). Unlike actual practice, perceived practice indicates self-confidence in doing activities related to folate. Among the questions on perceived practices, "intake of folic acid supplements even when not pregnant" and "belief that they have normal blood folate level" scored low at $61 \%$ and $43 \%$, respectively. It only shows that even if WOCBA knew that folate is important periconceptionally, the idea of taking it during a non-pregnant state may not be amenable for all respondents of this study. However, folate supplementation only when pregnant may be too late for some women to prevent the risk of NTDs. ${ }^{22}$ Moreover, unplanned pregnancies may put mother and child at risk of complications related to the deficiency of folate and other nutrients. The study also showed that respondents were interested in learning more about folate. Specifically, about $98 \%$ of respondents showed regard to learn how to achieve normal folate status and while $95 \%$ showed interest to learn ways to put it into practice.

The study showed a significant moderate association between knowledge and attitude $(r=0.7, p<0.000)$. A recent study of KAP on folate among female university students in Malaysia showed a weak association of knowledge to attitude. ${ }^{23}$ While both studies showed an association between knowledge and attitude, the age difference in the sample population might have affected the resulting strength of association. The present study suggested that the mean knowledge score was significantly associated with age. Moreover, a moderately positive association was found between knowledge and attitude $(r=0.5, \mathrm{p}<0.000)$. Further, attitude and perceived practice $(\mathrm{r}=0.4, \mathrm{p}<0.000)$ showed a weak positive association. Increasing the level of knowledge on folate may suggest a positive attitude and increased level of perceived practices among women respondents.

\section{CONCLUSION}

The study concludes that there is a moderate level of knowledge on folate, however, the rate of awareness is still low among WOCBA. Only about 70\% of WOCBA have heard of folate and among them, $80 \%$ have a little knowledge about it. While the result is at par with the neighboring countries, the remaining $30 \%$ of women who lack proper knowledge of folate is still alarming. Knowledge was associated with age and civil status. Knowledge level increases with education, however, a non-significant association was found. Likewise, attitude and perceived practices related to folate showed positive and high scores, respectively. High level of knowledge, positive attitude, and high level of perceived practices related to folate were observed among older women respondents (age 30 years and above), married or living with a partner, and with at least 12 years of education. The respondents also showed interest in learning more about folate and its importance, however, a lower number of respondents perceived that they should take folic acid supplementation even when not pregnant. Folate is a nutrient related to healthy pregnancy outcomes, but timing is critical. Adequate folate must be assured of even before being pregnant to reduce the chances of complications, such as NTDs. It is therefore crucial to convey this important piece of information as a preventive approach to reduce folate deficiency in women. Advocating intake of folate-rich food and proper intake and timing of folic acid supplements among WOCBA can result in a greater number of lives saved.

The findings of this study recommend a rigorous campaign to create and increase awareness among WOCBA of the importance of taking adequate folate and maintaining normal folate in the blood. Women who are planning to get pregnant must be informed to take folic acid supplementation 
to reduce the risk of complications related to folate deficiency. As part of antenatal care in primary health centers, health care providers must be trained on how to counsel women on advocating healthy pregnancy, such as, ensuring adequate folate intakes. The study recommends emphasizing the importance of not having enough folate as it not only causes mild complications but also, severe ones such as NTDs and fetal death. Also, the result of this study suggests that young women must be educated on the importance of folate in women's reproductive health. Further, WOCBA should be advised to eat more dark green leafy vegetables rich in folate as part of a balanced diet and take folic acid supplementations to combat folate deficiency. To educated the younger generation, the importance of folate may be included as a topic in the subject of health in the elementary and high school curriculum. NTDs are considered a rare disease. Universities may also take part in the celebration of rare disease week to create and increase awareness on the importance of nutrition to the proper development of infants during pregnancy. WOCBA should also be encouraged to seek reproductive health consultations regularly.

To the best of author's knowledge, this study is among the first to look into the assessment of KAP on folate among WOCBA. It draws relevance to the alarming prevalence of folate deficiency in the country which poses a significant economic burden. Therefore, this study is significant to fill the literature gap on KAP related to folate with a focus on women of reproductive age.

Moreover, the study reported a high response rate of $92 \%$. The KAP assessment tool used in the study was designed to include statements that directly reflect respondents' KAP on folate. These statements showed similarity to other previous KAP studies on folate outside the country. The result of KAP can provide valuable inputs for effective program planning related to the improvement of folate status in the target population. Besides, KAP studies contribute to a situation analysis by identifying gaps in the target group's knowledge, attitude, and perceived practice and highlighting priority needs in nutrition education.

Despite the strengths mentioned, this study poses limitations that may be considered fand included as part of future related researches. The study must include an equally represented number of women based on age to assess thoroughly KAP differences in age. It is also recommended to include obstetric history as variables of the study.

\section{Statement of Authorship}

The author of this article conceptualized, designed, implemented, analyzed and wrote the paper for publication.

The author participated in data collection and analysis, and approved the final version submitted.

\section{Author Disclosure}

The author declared no conflicts of interest.

\section{Funding Source}

This paper was funded by the Neys-van Hoogstraten Foundation (NHF) and Sight and Life.

\section{REFERENCES}

1. Tamura $\mathrm{T} \&$ Picciano MF. Folate and human reproduction. The American Journal of Clinical Nutrition. 2006 May; 83(5):993-1016. https://doi.org/10.1093/ajcn/83.5.993

2. Bailey RL, McDowell MA, Dodd KW, Gahche JJ, Dwyer JT \& Picciano MF. Total folate and folic acid intakes from foods and dietary supplements of US children aged 1-13 y. The American Journal of Clinical Nutrition. 2010 Jun; 92(2):353-8. https://doi.org/10.3945/ ajcn.2010.29652

3. Philippine Dietary and Reference Intakes. Food and Nutrition Research Institute - Department of Science and Technology (FNRIDOST). 2015. DOST Complex, FNRI Bldg., Bicutan, Taguig City, Metro Manila Philippines. Available from: https://www.fnri.dost.gov. $\mathrm{ph} /$ images/images/news/PDRI-2018.pdf

4. Desnacido JA, Cheong RL, Madriaga JR, Perlas IA \& Marcos JM. Folate status of Filipino women of childbearing age: Philippines 2008. [Internet]. [cited 2019 May]. Available from: http://122.53.86.125/ Seminar\%20Series/38th/folate\%20status_filipino\%20women.pdf

5. Pitkin RM. Folate and neural tube defects. The American Journal of Clinical Nutrition. 2007 Jan; 85(1):285S-8S. https://doi.org/10.1093/ ajcn/85.1.285S

6. David-Padilla C, Cutiongco-dela Paz E, Cavan BC, Abarquez C, Sur ALD, Sale RI, et al. Establishment of the Philippine Birth Defects Surveillance. Acta Med Philipp. 2011; 45 (4). [Internet]. [cited 2019 May]. Available from: https://www.google.com/url?sa=t\&rct=j\&q $=\&$ esrc $=$ \&\&source $=$ web \&cd $=\& v e d=2$ ahUKEwiB6_OEtafvAhWYyI sBHeOfBwoQFjAAegQIBxAD\&url=https\%3A\%2F\%2Fwww. actamedicaphilippina.org\%2Fapi\%2Fv1\%2Farticles\%2F7291establishment-of-the-philippine-birth-defects-surveillance.pdf\&usg= AOvVaw0J9XejUKB1h39rBQdBTfVd

7. Guidelines for assessing nutrition-related knowledge, attutide and practices. Food and Agriculture Organization of the United Nations (FAO). 2014. [Internet]. [cited $2020 \mathrm{Feb}$. Available from: http:// www.fao.org/3/i3545e/i3545e00.htm

8. Department of Health. The 2010 Philippine Health Statistics [Internet]. 2010 [cited 2020 Apr]. Available from: https://www.doh.gov.ph/sites/ default/files/publications/PHS2010_March13.compressed.pdf

9. Trevethan R. Deconstructing and Assessing Knowledge and Awareness in Public Health Research. Frontiers in Public Health. 2017 Aug; 5 (194): 1-6. https://doi.org/10.3389/fpubh.2017.00194

10. Bener A, Al Maadid MGA, Al-Bast DAE \& Al-Marr S. Maternal knowledge, attitude and practice on folic acid intake among Arabian Qatari women. Reproductive Toxicology. 2006 Jan; 21(1):21-25. https://doi.org/10.1016/j.reprotox.2005.07.004

11. Hisam A, Rahman MU \& Mashhadi SF. Knowledge, attitude and practice regarding folic acid deficiency; A hidden hunger. Pakistan Journal of Medical Sciences. 2014 May-Jun; 30(3), 583-588. https:// doi.org/10.12669/pjms.303.4716

12. Rehan M, Mahmood N \& Mazhar SB. Knowledge, Attitude and Practices Regarding Periconceptional Folic Acid Supplementation in a Tertiary Care Hospital. Ann. Pak. Inst. Med. Sci. 2015; 11(4):1725. [Internet]. [cited 2019 May]. Available from: https://apims.net/ apims_old/Volumes/Vol11-4/Knowledge\%20Attitude\%20and\%20 Practices\%20Regarding\%20Periconceptional\%20Folic\%20Acid.pdf

13. Keshavarzi F, Choong MT, Mun Yi W \& Haliza Yusoff N. Periconceptional Folic Acid Usage Pattern in Malaysian Women. 2016 Aug; 8:1199-1204. [Internet]. [cited 2019 May]. Available from: https://www.researchgate.net/profile/Fazlollah-Keshavarzi/ publication/306065379_Periconceptional_Folic_Acid_Usage_ Pattern_in_Malaysian_Women/links/57ad8aa908ae3765c3bbbe15/ Periconceptional-Folic-Acid-Usage-Pattern-in-Malaysian-Women. pdf 
14. Bitzer J, von Stenglin A \& Bannemerschult R. Women's awareness and periconceptional use of folic acid: data from a large European survey. International Journal of Women's Health. 2013 Apr; 5:201-13. https://doi.org/10.2147/IJWH.S40149

15. Kim MJ, Kim J, Hwang EJ, Song Y, Kim H \& Hyun T. Awareness, knowledge, and use of folic acid among non-pregnant Korean women of childbearing age. Nutrition Research and Practice. 2018 Jan; 12(1):78-84. https://doi.org/10.4162/nrp.2018.12.1.78

16. Kondo A, Kamihira O, Shimosuka Y, Okai I, Gotoh M \& Ozawa H. Awareness of the role of folic acid, dietary folate intake and plasma folate concentration in Japan. Journal of Obstetrics and Gynaecology Research. 2005 Mar; 31(2):172-7. https://doi.org/10.1111/j.13418076.2005.00265.x

17. Zeng Z, Yuan P, Wang Y, Ma X \& Zhu J. Folic acid awareness and intake among women in areas with high prevalence of neural tube defects in China: a cross-sectional study. Public Health Nutrition. 2011 Feb; 14(7):1142-7. https://doi.org/DOI: 10.1017/ S1368980011000097

18. Horn F, Sabova L, Pinterova E, Hornova J \& Trnka J. Prevention of neural tube defects by folic acid - awareness among women of childbearing age in Slovakia. Bratislavske lekarske listy. 2014; 115(2):91-97. https://doi.org/10.4149/bll_2014_020
19. Prue C., Hamner HC \& Flores AL. Effects of Folic Acid Awareness on Knowledge and Consumption for the Prevention of Birth Defects Among Hispanic Women in Several U.S. Communities. Journal of Women's Health. 2010 Apr; 19(4):689-98. https://doi.org/10.1089/ jwh.2009.1573

20. Vollset SE \& Lande B. Knowledge and attitudes of folate, and use of dietary supplements among women of reproductive age in Norway 1998. Acta Obstetricia et Gynecologica Scandinavica. 2009 Aug; 79(6):513-9. https://doi.org/10.1080/j.1600-0412.2000.079006513.x

21. Organization for Economic Co-operation and Development, Measuring the effects of education on health and civic engagement: Proceedings of the Copenhagen Symposium [Internet]. 2006 [cited $2020 \mathrm{Apr}$. Available from: http://www.oecd.org/education/ innovation-education/37425753.pdf

22. National Academy of Science and Technology. NAST PH calls for the need for folic acid [Internet]. n.d [cited 2020 May]. Available from: https://www.nast.ph/index.php/13-news-press-releases/226-nast-phlcalls-for-the-need-for-folic-acid

23. Yusof AY \& Tajuddin NA. Knowledge, attitude and practice (KAP) regarding folate intake among female students in International Islamic University Malaysia (IIUM) Kuantan, International Journal of Public Health and Clinical Sciences. 2020; 7 (1):45-57. https:// doi.org/10.32827/ijphcs.7.1.45 